\title{
Self-assembled plasmonic templates produced by microwave annealing: Applications to surface-enhanced Raman scattering
}

\author{
N.T. Panagiotopoulos ${ }^{1}$, N. Kalfagiannis ${ }^{2,3}$, K. Vassilopoulos ${ }^{1}$, N. Pliatsikas ${ }^{4}$, S. Kassavetis ${ }^{1}$, G. \\ Vourlias $^{4}$, M.A. Karakassides ${ }^{1}$, and P. Patsalas ${ }^{1,4, *}$ \\ ${ }^{1}$ University of Ioannina, Department of Materials Science and Engineering, GR-45110 Ioannina, Greece \\ ${ }^{2}$ Texas A\&M University at Qatar, Department of Petroleum Engineering, 23874 Doha, Qatar \\ ${ }^{3}$ Nottingham Trent University, School of Science and Technology, Nottingham, NG11 8NS, United Kingdom \\ ${ }^{4}$ Aristotle University of Thessaloniki, Department of Physics, GR-54124 Thessaloniki, Greece \\ *corresponding author: ppats@physics.auth.gr,
}

\begin{abstract}
Perhaps the simplest method for creating metal nanoparticles on a substrate is by driving their selfassembly with the thermal annealing of a thin metal film. By properly tuning the annealing parameters one hopes to discover a recipe that allows the pre-determined design of the nanoparticle (NP) arrangement. However, thermal treatment is known for detrimental effects and is not really the manufacturer's route of choice when it comes to largescale applications. An alternative method is the use of microwave annealing, a method that has never been applied for metal processing, due to the high reflectance of microwave radiation at the surface of a metal. However, in this work we challenge the widely used nanostructuring methods by proving microwave's annealing ability to produce plasmonic templates, out of extremely thin metal films, by simply using a domestic microwave oven apparatus. We show that this process is generic and independent of the deposition method used for the metal and we further quantify the suitability of these plasmonic templates for use in surface-enhanced Raman scattering applications.
\end{abstract}

KEYWORDS: Plasmonics; Nanoparticles; Microwave Annealing; SERS.

\section{INTRODUCTION}

The physics of nanosized metal particles gained significant attention due to their exceptional functionality, extreme chemical activity and the strong electromagnetic phenomena that manifest at the nanoscale. In particular, the study of the Localized Surface Plasmon Resonance (LSPR), a collective oscillation of the metals' conduction electrons accompanied by extreme near-field enhancement, led to myriads of publications and promises groundbreaking applications in everyday life, such as biosensing [1,2], photonic and microelectronic devices [3-5], and optical storage of information [6]. Among these applications, surface-enhanced Raman scattering (SERS) and surfaceenhanced resonant Raman scattering (SERRS) were extensively studied [7-13] because of both the fundamental science lying behind them, as well as due to the tremendous social impact of their application to early medical diagnosis, as well as to toxicology and forensics [14-16]. Plasmonic templates, consisting of nanoparticles supported on a substrate, are nowadays produced by a wide range of growth techniques spanning from chemical synthesis in colloidal solutions [17-20], to templated synthesis on rigid substrates by nanosphere lithography [21,22], electron-beam lithography [23,24], block copolymer nanolithography [25] and laser annealing of $\mathrm{Ag}$ thin films [26,27]. However, there is still a need for new fabrication routes that would be facile, fast, costeffective, accurate and highly reproducible, and that would require a lesser degree of sophistication compared to lithographic techniques and laser annealing, and would produce nanoparticles that are firmly attached to the substrate (which acts as the test plate for diagnosis and forensics when SERS/SERRS is implemented), in contrast to the colloidal solutions.

In this work, we propose a new fabrication route that combines all the aforementioned requirements and assets. It is based on the microwave annealing (MWA) of thin metal deposits on $n$-type $\mathrm{Si}$ wafers in a domestic microwave oven. Microwave processing is an attractive approach due to the reduced times, increased uniformity, improved reproducibility and selective heating; in addition, it was reported that the use of microwaves results in lower processing temperatures [28]. The microwave processing proposed in this work is generic and independent of the deposition method used for the metal, but it is strongly substrate- and metal- dependent. We show that metal deposits on insulating substrates (such as sapphire and borosilicate glass) are not reshaping upon MWA proving that the microwave energy is delivered to the Si substrate and not to the film itself; this is because the used metal deposits were thinner than the skin depth of the corresponding metal, while doped $\mathrm{Si}$ is known to absorb strongly the microwave radiation [29-31].

We present an in-depth investigation of the experimental parameters, such as: 1) the metal itself (Ag, $\mathrm{Au}, \mathrm{Cu}$ and $\mathrm{Sn}), 2$ ) the deposition method (magnetron sputtering, electron beam evaporation and electroless reduction of $\mathrm{AgNO}_{3}$ on $\mathrm{Si}$ [32]), 3) the thickness of the metal deposit, and 3) the MWA processing time. In addition, we consider the reproducibility of the fabrication of plasmonic templates by MWA, and their spatial homogeneity which is challenged by the edge effects that apply both to the electric field enhancement 
and the different heat flow conditions at the edges. This study is supported by a wide variety of analytical techniques such as Atomic Force Microscopy (AFM), XRay Photoelectron Spectroscopy (XPS), X-Ray Reflectivity (XRR), X-Ray Diffraction (XRD), Optical Reflectance Spectroscopy (ORS) and Raman spectroscopy. Finally the suitability of the produced plasmonic templates as SERRS test plates was evaluated by performing detailed SERRS measurements of aqueous solutions of Rhodamine 6G (R6G), which is a standard test molecule for SERS/SERRS [26,27,33-35].

\section{EXPERIMENTAL}

The plasmonic templates have been produced in a two step process. Initially an ultra-thin layer of a metal $(\mathrm{Ag}$, $\mathrm{Au}, \mathrm{Cu}$, or $\mathrm{Sn}$ ) was deposited on $30 \times 30 \mathrm{~mm}^{2}$ square pieces of cleaved standard, $n$-type prime $\mathrm{Si}(100)$ wafers (resistivity $1-10 \Omega \mathrm{cm}$ ) by sputtering (all metals), electron beam evaporation (Ag) and Electroless Reduction of silver(Ag) Nitrate (ERAN) [32]; the deposits had effective thickness in the range of 3-14 $\mathrm{nm}$, which was accurately measured by XRR. Especially for the case of gold deposition, a miniature, low vacuum $\left(\mathrm{P}_{\mathrm{b}}=10^{-2} \mathrm{mbar}\right)$ sputter coater, which is intended for the preparation of scanning electron microscope specimens, was implemented. The target was a gold foil (purity of 99.99\%) covering the 1" copper electrode of the coater. The rest of the sputtered layers were deposited in a high vacuum $\left(\mathrm{P}_{\mathrm{b}}<5 \times 10^{-6}\right.$ mbar) sputtering device using a 2 ', $99.99 \%$ pure metal target equipped with a rotating sample holder and a $5 \mathrm{~W}$ RF-power (13.56 MHz). The evaporated samples were deposited in a standard Edwards vacuum coater $\left(\mathrm{P}_{\mathrm{b}}<5 \times 10^{-7} \mathrm{mbar}\right)$. The thickness of all the layers varied by controlling the deposition time in all coaters. The details of the electroless reduction of $\mathrm{AgNO}_{3}$ on $\mathrm{Si}$ are presented elsewhere [32].

The second processing step is based on microwave annealing of the produced metal $/ n-\mathrm{Si}$ geometry. The samples have been placed on $3 \mathrm{~cm}$ silica podium in the center of the microwave cavity of a domestic appliance (Sharp), and exposed to $900 \mathrm{~W}$ microwave power for 3$60 \mathrm{~s}$. Metal deposits on sapphire, borosilicate glass and ITO/borosilicate glass were also processed by MWA for comparison purposes. Selected samples were thermally annealed on a hot plate at $350{ }^{\circ} \mathrm{C}$ for comparison purposes, as well.

The structural features of the produced templates were studied in terms of surface morphology, density, metal coverage of $\mathrm{Si}$ and crystal size in terms of AFM (Nanoscope and Dimension Icon both by BRUKER) in tapping mode, X-Ray Reflectivity (XRR) (Bruker D8Advance), XPS (SPECS GmbH, twin Al-Mg anode source and a Phoibos-100 hemispherical sector analyzer), and XRD (Bruker D8-Advance with the Lynxeye linear strip solid state detector), respectively.
The size of the particles was derived though grain analysis of $2 \times 2 \mu \mathrm{m}^{2}$ AFM images. A direct comparison on the size and the shape of the particles before and after microwave annealing was possible through the acquisition of detailed high resolution AFM images (at $500 \mathrm{~nm}$ ) and subsequent cross section analysis.

The far-field optical properties of the plasmonic templates have been investigated in terms of spectral reflectivity measurements at vertical incidence in the spectral range 250-780 $\mathrm{nm}$ (although only the 400-750 $\mathrm{nm}$ range is relevant to the SERRS application). Finally, SERRS measurements were acquired in a RENISHAW 1000 micro-Raman spectrometer using a $\times 50$ focusing and a $0.3-5 \mathrm{~mW} \mathrm{Nd}$ :YAG $(532 \mathrm{~nm})$ or $\mathrm{He}-\mathrm{Ne}(633 \mathrm{~nm})$ laser radiation. The Raman spectra were calibrated using the peak originating from the underlying Si substrate. The SERRS measurements were carried out after dipping the plasmonic templates for $3 \mathrm{~s}$ in R6G aqueous solutions $\left(10^{-3}-10^{-9} \mathrm{M}\right)$, ultrasonication in deionized water for 5 min and finally drying with pure $\mathrm{N}_{2}$ gas. Note that by this testing process the attached R6G molecules on the surface are substantially fewer than what would be expected for a process including drop-casting and drying of the solution or long time sedimentation of R6G on the template; we implement this process in order to evaluate the produced test plates in realistic conditions of fast testing.

\section{RESULTS AND DISCUSSION}

\section{A. Structural and chemical features}

While microwave annealing is a well-known processing method for ceramics [36-38], it has not been implemented for metals for the fundamental reason of the skin depth of microwave radiation at the surface of metals being exceptionally small; as a result, the microwave energy is reflected by the metal surface and is not delivered to the material itself. However when the size of the metal is comparable or smaller than the skin depth of microwave radiation, the energy of the electric field can pass through it and delivered to the substrate [39]. Our approach is based upon the annealing of the underlying $\mathrm{Si}$ substrate in a domestic microwave oven operating at $900 \mathrm{~W}$, where ultrathin metal films (thinner or comparable to the skin depth and their percolation threshold [40]) have been grown. The temperature of the annealed Si can be as high as $400{ }^{\circ} \mathrm{C}$ (measured in-situ by an IR-emission thermal camera) making $\mathrm{Si}$ to act as a uniform hot plate and probing melting and resolidification of the metal layer with severe morphological and structural changes that are shown in Fig. 1. In particular, Figs. 1-a1, 1-b1 and 1-c1 show the AFM topographic images of three ultrathin films of $\mathrm{Ag}$ grown on Si by three individual techniques: MS, EBE and ERAN, respectively. The roughness and complexity of the $\mathrm{Ag}$ surfaces is varying, depending on the 
deposition technique, and is characterized by irregularly shaped Ag islands. The studied sputtered Au (Fig. 1-d1), $\mathrm{Sn}$ (Fig.1-e1) and $\mathrm{Cu}$ (not shown) exhibit a grainy morphology resembling the surface morphology of sputtered Ag (Fig. 1-a1).
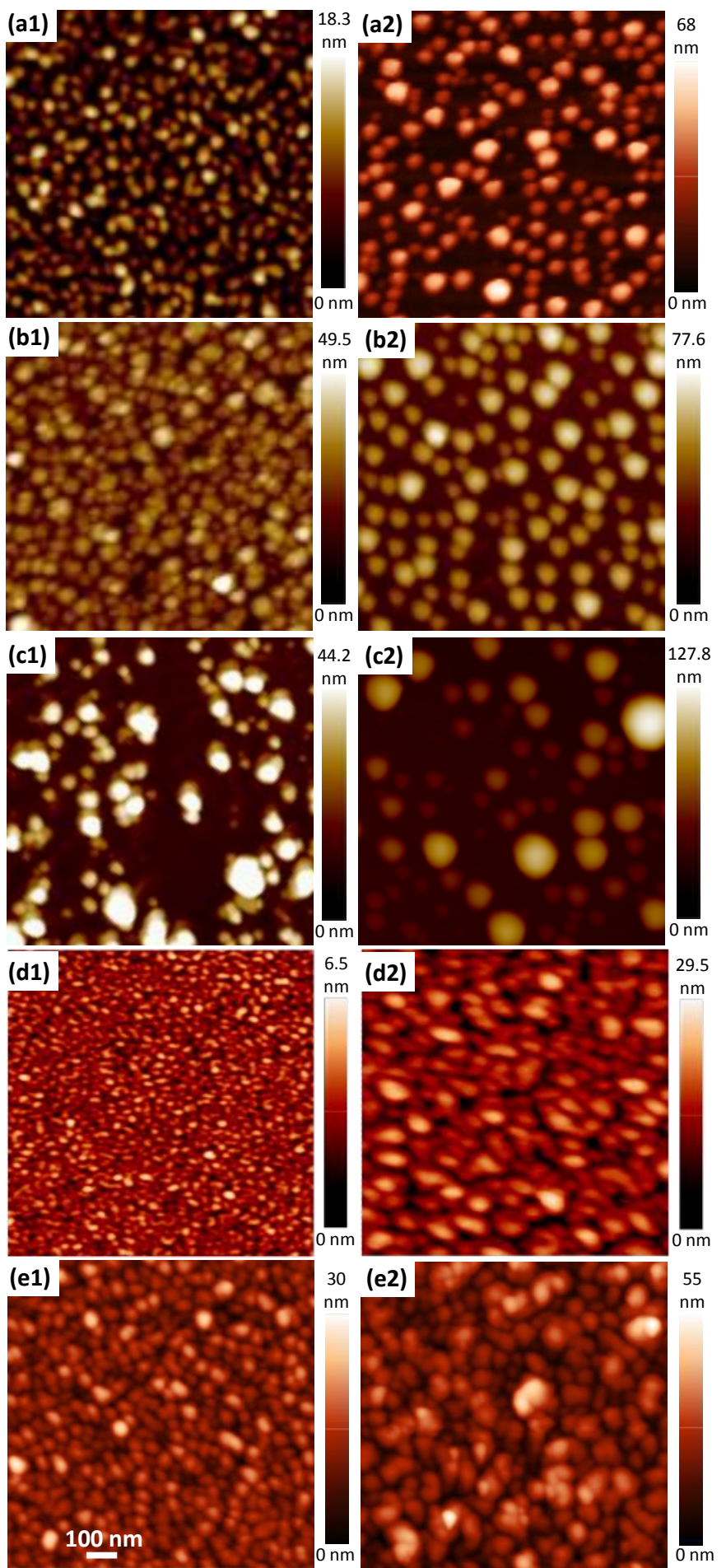

Fig. 1: AFM images from representative metal layers on $\mathrm{Si}$ : (a1) Ag, as grown MS, (b1) Ag, as grown EBE, (c1) Ag, as grown ERAN, (d1) Au, as grown MS, (e1) Sn, as grown MS, and (a2) Ag, MWA MS, (b2) Ag, MWA EBE, (c2) Ag, MWA ERAN, (d2) Au, MWA MS, (e2) Sn, MWA MS.

After MWA all the Ag films were transformed to well-defined and isolated $\mathrm{Ag}$ islands of regular shapes (spherical sectors, see Figs. 1-a2, 1-b2 and 1-c2) showing that this method has a universal potential and can be applied for the formation of $\mathrm{Ag}$ nanoparticles independently of the deposition method of Ag. The melting of $\mathrm{Ag}$ at such low annealing temperature $(\leq 400$ ${ }^{\circ} \mathrm{C}$ ) is due to the very small size of the $\mathrm{Ag}$ grains in the as-deposited ultra-thin films, because the melting point of $\mathrm{Ag}$ is reducing with the particle size [41-43]. On the other hand, MWA of thin metal layers deposited on ceramics (borosilicate glass, silica, sapphire) did not exhibit any morphological and/or structural alteration upon MWA. It is worth noting that due to the fine particle distribution of $\mathrm{Ag}$ in all cases, there is also substantial diffusion at the used low temperature, since the observed average sizes after MWA were bigger than what was found for the as deposited films, as shown in Fig 2, possibly due to an Ostwald ripening process [44]. The morphology and the enlargement of the $\mathrm{Ag}$ nanoparticles after MWA, that are also demonstrated in the size distributions and cross section AFM line scans shown in the insets of Fig. 2, would be also explained, if we took into account that for crystallization temperatures well below the melting point of bulk $\mathrm{Ag}\left(961.93{ }^{\circ} \mathrm{C}\right)$ the wetting of $\mathrm{Ag}$ on the $\mathrm{Si}(100)$ surface is very poor, and contact angles on $\mathrm{Si}$ as high as $110^{\circ}$ were reported [45]. This provides the shape regularity of the formed $\mathrm{Ag}$ nanoparticles observed in Fig. 1.

The formation of nanoparticles after fast MWA was also confirmed by XRR and XPS (refer to the on line supporting information). XRR indicated increasing roughness and effective thickness and loss of average density after MWA, providing supporting evidence for the formation of isolated nanoparticles with free space among them. This is further supported by XPS, which shows that the surface coverage of $\mathrm{Si}$ by $\mathrm{Ag}$ is substantially reduced after MWA. XPS shown that the $\mathrm{Ag}$ nanoparticles on $\mathrm{Si}$ are in metallic state, and no traces of silver oxides were detected.

The aspect ratio (height/diameter) of most cases of formed $\mathrm{Ag}$ particles was close to $1 / 2$ indicating the formation of hemispheres, while the observed contact angles of $\mathrm{Ag}$ on $\mathrm{Si}$ were ranging between 60 and $90^{\circ}$; this is clearly demonstrated in the insets of Fig. 2. However, for thicker $\mathrm{Ag}$ films $(>12 \mathrm{~nm})$ the aspect ratio is substantially smaller, indicating a smaller contact angle or a platelet-like morphology. This is even more pronounced for the case of $\mathrm{Au}$ films as it is shown in AFM image of Fig. 1-d2. The observed aspect ratios for $\mathrm{Au}$ are mostly within the range of $0.20-0.25$, which are unequivocally smaller than the aspect ratio of any spherical sector and, therefore, are attributed to platelet morphology. The variations in aspect ratio are possibly due to the gravitational forces that are not negligible for larger liquid heavy metal droplets/nanoparticles [46]. The MWA processes was also applied to Sn films on Si (Fig. 1-e1) and resulted in the formation of nanoparticles larger than $100 \mathrm{~nm}$ and aspect ratio close to $1 / 2$ (Fig. 1e2); the observed large size and aggregation of the formed Sn particles and the high aspect ratio is attributed 
to the low melting point of $\mathrm{Sn}\left(232^{\circ} \mathrm{C}\right)$ and the very high contact angle of Sn on Si surfaces [45]. On the contrary, $\mathrm{Cu}$ films grown on $\mathrm{Si}$ did not exhibit any morphological difference (not shown) after MWA due to the relatively high melting point of $\mathrm{Cu}\left(1084.62{ }^{\circ} \mathrm{C}\right)$ and mostly due to the good wetting of $\mathrm{Cu}$ on $\mathrm{Si}$ [47]. The melting points, the morphologies after MWA, the average particle sizes and the spectral position of the LSPR of the considered metals are summarized in Table I.

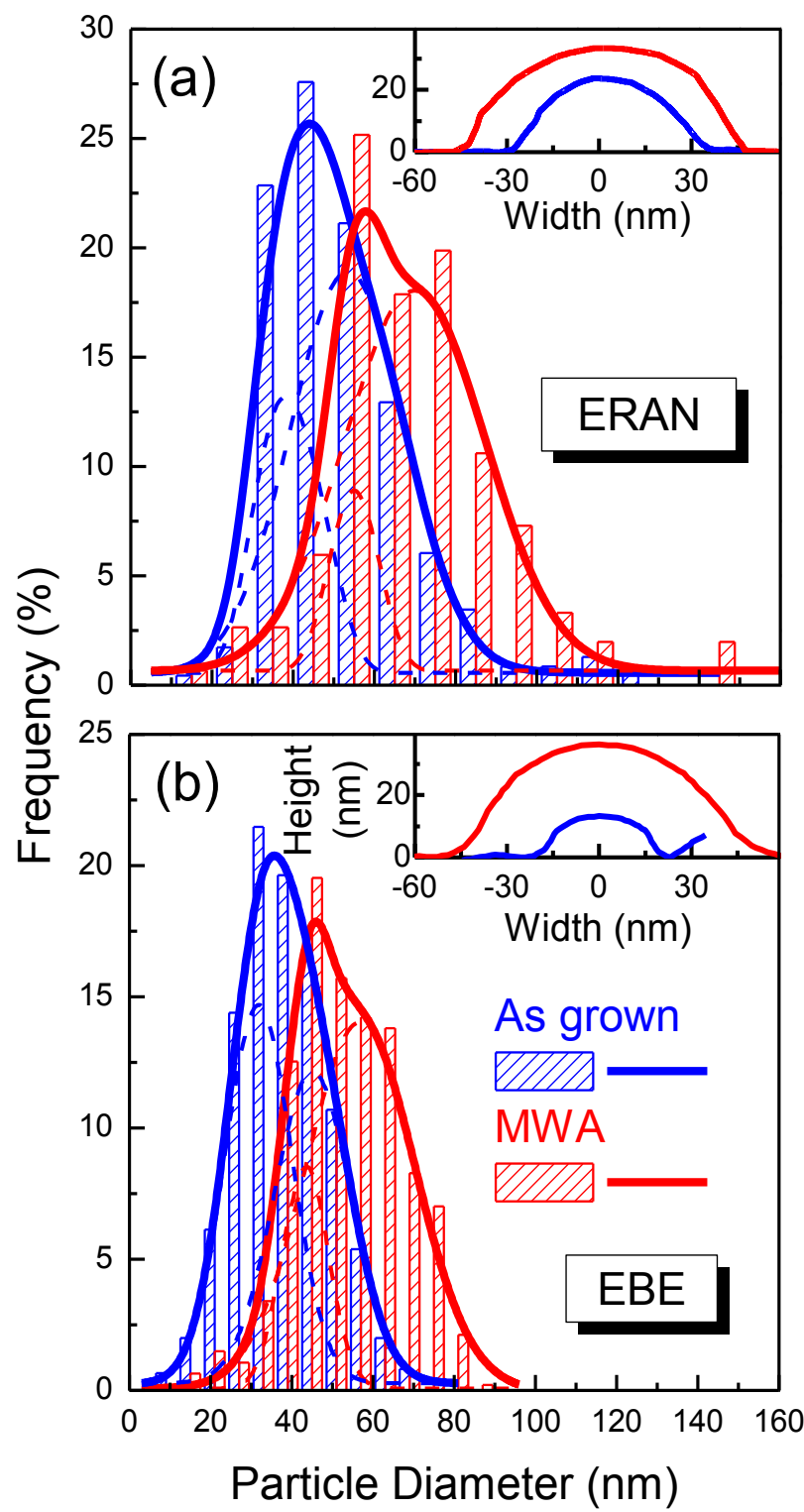

Fig. 2: Size distributions of Ag nanoparticles before and after MWA for the representative Ag films grown by (a) ERAN, and (b) EBE. The corresponding insets show representative cross section AFM line scans revealing the shape of particles and contact angles of $75^{\circ}$ and $64^{\circ}$ for ERAN and EBE samples after MWA, respectively.

Table I: The metal thin films used for MWA

\begin{tabular}{|l|c|c|c|c|}
\hline & Sn & $\mathbf{A g}$ & $\mathbf{A u}$ & $\mathbf{C u}$ \\
\hline Melting point $\left({ }^{\circ} \mathbf{C}\right)$ & 232 & 961.93 & 1064.78 & 1084.62 \\
\hline $\begin{array}{l}\text { Particle } \\
\text { shape/nature }\end{array}$ & $\begin{array}{c}\text { Coalesced } \\
\text { Islands }\end{array}$ & $\begin{array}{c}\text { Spherical sector/ } \\
\text { Platelet }\end{array}$ & Platelet & $\begin{array}{c}\text { Continuous } \\
\text { Layer }\end{array}$ \\
\hline Particle size (nm) & $30-150$ & $30-200$ & $40-130$ & N/A \\
\hline LSPR (nm) & N/A & $470-750$ & $520-630$ & N/A \\
\hline
\end{tabular}

B. Optical properties of plasmonic templates
The varying size distributions of metal nanoparticles, as well as their isolation after MWA result in strong plasmonic response that may cover the whole visible spectral range by changing the effective thickness of the deposited metal on $\mathrm{Si}$, as shown by the optical reflectivity spectra presented in Fig. 3. In particular, Fig. 3 shows optical reflectivity spectra from various representative metal films (mostly $\mathrm{Ag}$ and $\mathrm{Au}$ ) of varying thickness (3-10 nm) and deposited by various techniques (MS, EBE and ERAN) after MWA. The square insets are real photo images of the optical appearances of a blue, a green and a red sample recorded by a digital camera. The optical reflectivity spectra of pure Si (black solid line) and of two Ag films (grown by MS and EBE and represented by gray dashed and dotted lines, respectively), deposited on $\mathrm{Si}$ before MWA, are also shown for comparison. It is evident that in most cases the assemblies of $\mathrm{Ag}$ nanoparticles after MWA exhibit stronger LSPR than Au; this is an expected behavior due to the overlap of interband and intraband absorption in gold [48].

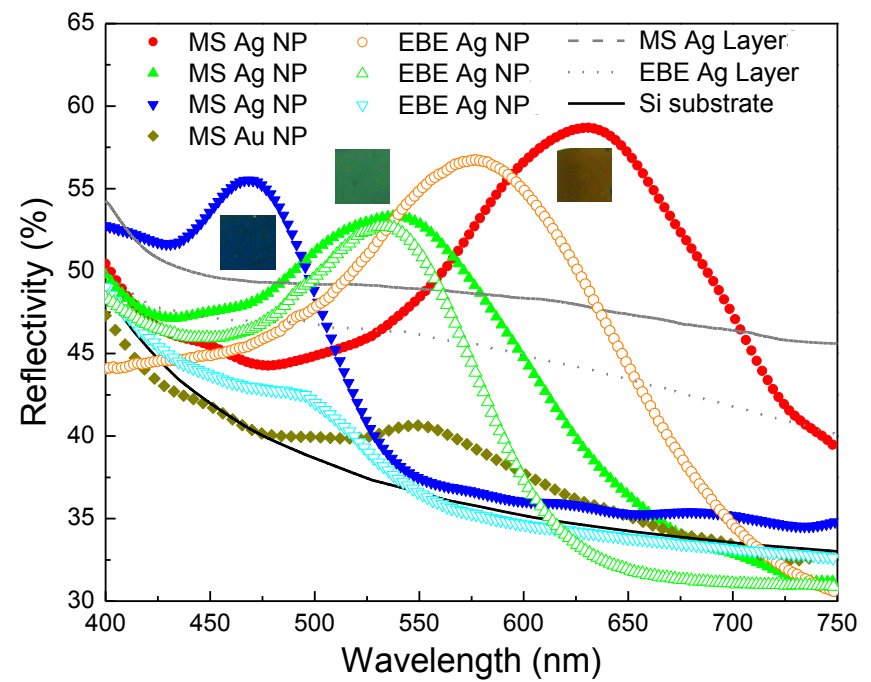

Fig. 3: Optical reflectivity spectra from various representative $\mathrm{Ag}$ and $\mathrm{Au}$ films of varying thickness and deposited by various techniques after MWA. The square insets are real images of the optical appearance of blue, green and red Ag nanoparticle assemblies. The optical reflectivity spectra of pure $\mathrm{Si}$ and two Ag films on Si before MWA are also shown for comparison.

In order to quantify the plasmonic response of the produced nanoparticles and to correlate it with the experimental growth and processing parameters, we report in Fig. 4 the spectral position of LSPR, as well as the reflectivity enhancement $\Delta R=R_{\text {nanoparticles }}-R_{S i}$ at the LSPR wavelength (where $R_{\text {nanoparticles }}$ and $R_{S i}$ are the absolute reflectivity values of the nanoparticles and the bare $\mathrm{Si}$ substrate) for a wide variety of metal films of varying elements $(\mathrm{Ag}$ and $\mathrm{Au})$, effective thickness (3-15 $\mathrm{nm}$ ), deposition method (MS, EBE and ERAN), annealing method (MWA or hot-plate thermal annealing (HPA)), and MWA processing time (3-60 s). There is a general trend of spectral redshift of LSPR $v s$. the metal 
film's effective thickness for the same sets of samples (i.e. films of the same element, deposited by the same method and processed in the same manner), which is associated with the average size of particles formed after MWA. Of particular interest are the sets of sputtered $\mathrm{Ag}$ films processed by MWA for $10 \mathrm{~s}$ (red disks) and by HPA at $350{ }^{\circ} \mathrm{C}$ for $90 \mathrm{~s}$ (blue triangles), because they demonstrate the equivalence of MWA and HPA. It is noteworthy that for Ag effective thickness up to $12 \mathrm{~nm}$ there is a complete equivalence of MWA and HPA, while for the thicker $14 \mathrm{~nm}$ film there is non-negligible difference in the LSPR performance between samples processed by MWA and HPA possibly due to the skin effect for microwaves. Also note that for thicker films $(>14 \mathrm{~nm})$ there is a substantial health and safety issue as sparks may be ignited in the microwave oven. A similar behavior is also observed for $\mathrm{Au}$ (open black squares for MWA and open blue triangles for HPA) (see also the on line supporting information).

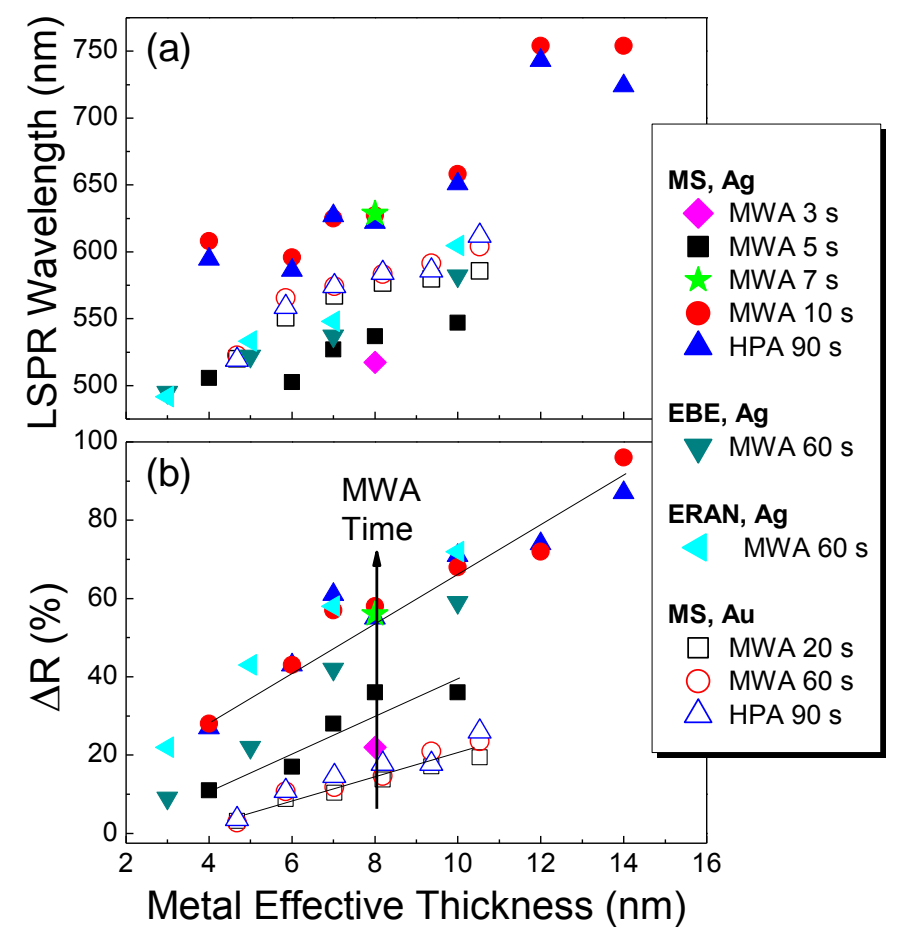

Fig. 4: The variation of the (a) LSPR wavelength, and (b) the reflectivity enhancement at LSPR with respect to the $\mathrm{Si}$ substrate $v s$. the effective metal thickness before MWA.

A major asset of MWA is the excellent reproducibility. We have repeated the sample preparation for tens of times in order to report statistically significant reproducibility data and we concluded that MWA can be reproducible with a tolerance of only $\pm 1.5 \%$ for the LSPR spectral position (see also the on line supporting information). In addition, we observed repeatedly an edge effect (i.e. different spectral position of LSPR at the edges of the sample) possibly due to the different electromagnetic field at the edges of a conductor, as well as the different heat dissipation conditions at the edges (for more details refer also to the on line supporting information).
Another issue is the strength of LSPR, expressed by $\Delta R$, of $\mathrm{Ag}$ nanoparticle templates produced by different deposition methods and MWA, which exhibit LSPR at similar spectral positions. For this case, it is appropriate to compare the $\mathrm{Ag}$ samples produced by sputtering after 5 s of MWA (Fig. 4, black squares), EBE and ERAN after $60 \mathrm{~s}$ of MWA (Fig. 4, dark cyan and cyan triangles, respectively) with $7 \mathrm{~nm}$ effective thicknesses. An increasing LSPR strength is observed, progressing gradually from the sputtered to the $\mathrm{EBE}$ and finally to ERAN deposited Ag after MWA, which indicates increasing isolation of $\mathrm{Ag}$ nanoparticles and elimination of aggregation for ERAN [49].

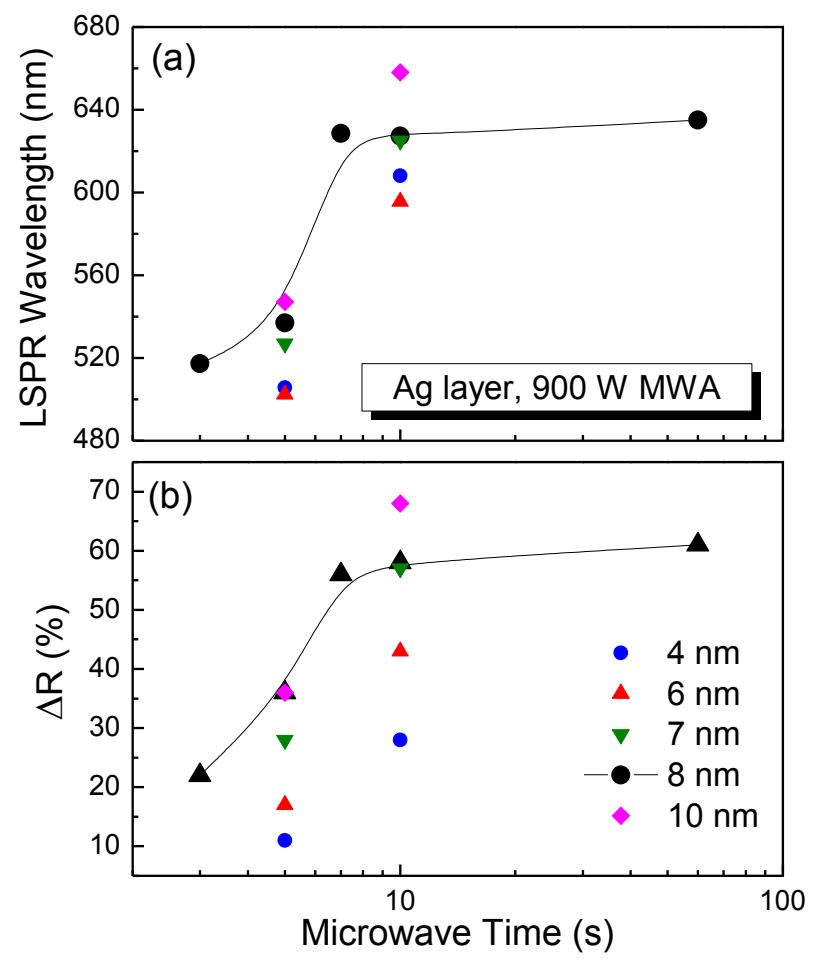

Fig. 5: The variation of the (a) LSPR wavelength, and (b) the reflectivity enhancement at LSPR with respect to the Si substrate $v s$. the MWA time.

From the previous discussion it is evident that MWA for $5 \mathrm{~s}$ is not enough to produce well-isolated $\mathrm{Ag}$ nanoparticles. In order to clarify the effect of MWA time we consider the evolution of the LSPR wavelength and $\Delta \mathrm{R}$ values for various MWA times for $\mathrm{Ag}$ films. The relevant results are presented in Fig. 5. Increasing the MWA time, from $5 \mathrm{~s}$ to $10 \mathrm{~s}$, results in substantial red shift of LSPR, which indicates the formation of bigger particles via the promotion of surface diffusion. $\Delta \mathrm{R}$ is also increasing due to the combined effect of reduced electromagnetic losses at LSPR due to larger particle size, as well as the better separation and isolation of the nanoparticles [49]. XRD analysis (see the on line supporting information) confirmed the optical observations and it shows that MWA for duration up to $10 \mathrm{~s}$ promote the grain size enhancement along the vertical direction from 8 to $18 \mathrm{~nm}$ with an accompanying substantial reduction of the macro-strain of $\mathrm{Ag}$ grains. MWA processing times longer than $10 \mathrm{~s}$ did not result in 
further improvement of LSPR and crystallographic characteristics of Ag.

\section{Application to SERRS}

The plasmonic efficiency of the produced nanoparticle templates was evaluated using SERRS measurements. In particular, two sets of sputtered Ag (effective thickness $10 \mathrm{~nm}, 5 \mathrm{~s}$ of MWA, LSPR at $545 \mathrm{~nm}$; effective thickness $10 \mathrm{~nm}, 5 \mathrm{~s}$ of MWA, LSPR at $545 \mathrm{~nm}$ ) and one set of $\mathrm{Au}$ (effective thickness $6 \mathrm{~nm}, 20 \mathrm{~s}$ MWA time, LSPR at $559 \mathrm{~nm}$ ) samples were dipped for $2 \mathrm{~s}$ in aqueous solutions of Rhodamine 6G (R6G) of various molar concentrations ranging from $1 \mathrm{nM}$ to $1 \mathrm{mM}$. Then the samples were rinsed by deionized water and were ultrasonically cleaned in pure deionized water, in order to remove any non-adsorbed R6G deposits from the surface. Note that the used protocol is very challenging because of the exceptionally short dipping time and the meticulous removal of any excess R6G; therefore, our results are focusing in fast diagnostics, that would be compatible with demands of clinical and forensic conditions and timeframes, and should not be compared with SERS or SERRS testing using long time protocols based on drying of the solution or sedimentation of R6G for several days. For our testing we used both the $532 \mathrm{~nm}$ $\left(2^{\text {nd }}\right.$ harmonic, $\left.\mathrm{Nd}: \mathrm{YAG}\right)$ and $633 \mathrm{~nm}(\mathrm{He}-\mathrm{Ne})$ excitation lasers in order to induce either SERRS or SERS emission from R6G, respectively; however, the SERRS signal (532 $\mathrm{nm}$ excitation) was substantially stronger in all cases, so we choose to report only the SERRS spectra and analysis in this communication. All the spectra were acquired with the same integration time and number of accumulations in order to be comparable to each other. It should be noted that no Raman signal were detected for 1 $\mathrm{mM}$ concentration of R6G drop casted on glass slide, while the untreated sputtered Ag film provided a hardly detectable Raman signal for $1 \mathrm{mM}$ R6G.

Figure 6 shows representative SERRS spectra from sputtered Ag films, after MWA exhibiting LSPR at 633 $\mathrm{nm}$, exposed at various concentrations of R6G; note the background, due to fluorescence, was subtracted from the spectra (for the raw data that include the fluorescence contribution refer to the on line supporting information). The recorded spectra include all the expected Raman peaks of R6G [50] for concentrations between $1 \mathrm{mM}$ and $10 \mu \mathrm{M}$. For smaller concentrations only the stronger peaks have a meaningful signal-to-noise ratio. In Table II we compare the detection of the reference R6G Raman peaks (from Hildebrandt and Stockburger [50]) at various concentrations of R6G on the Ag nanoparticle templates with LSPR at $633 \mathrm{~nm}$. The peaks that are detected even for the lowest concentration are those assigned to aromatic C-C stretching modes of R6G at 1361, 1506 and $1647 \mathrm{~cm}^{-1}$. Other modes that were detected for relatively low R6G concentrations are the $\mathrm{C}-\mathrm{C}-\mathrm{C}$ ring mode at 610 $\mathrm{cm}^{-1}$ and the $\mathrm{C}-\mathrm{H}$ out of plane bend mode at $771 \mathrm{~cm}^{-1}$.

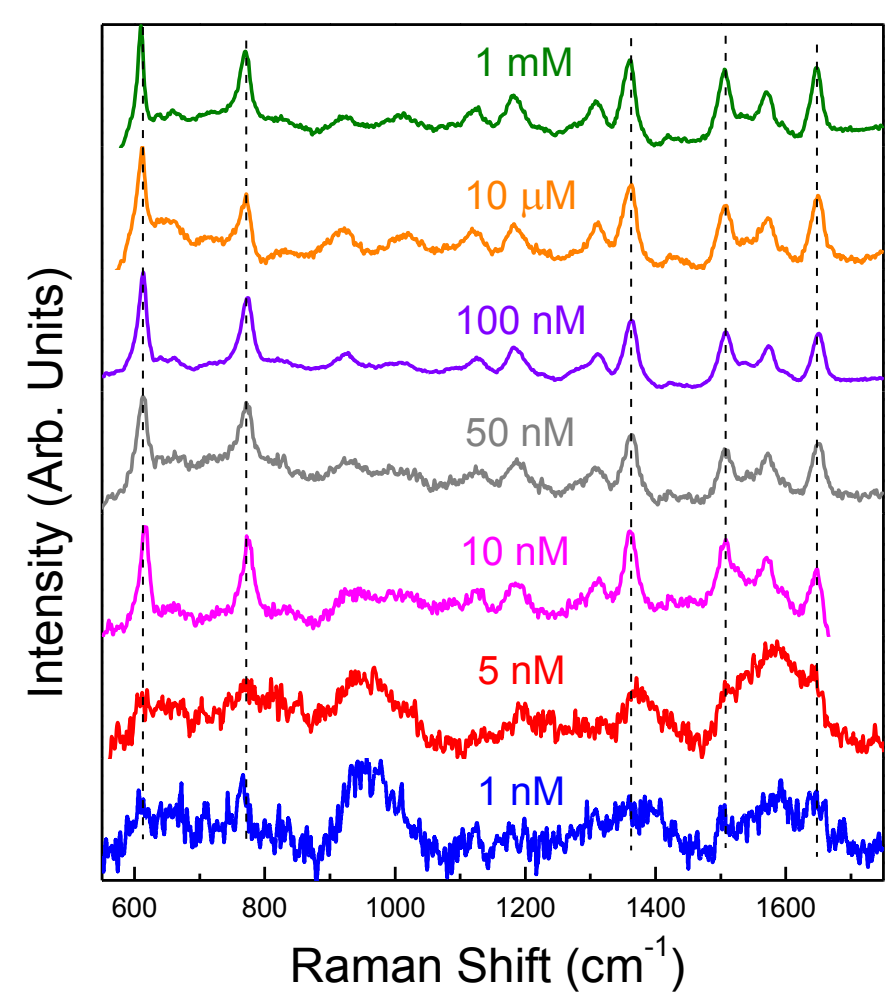

Fig. 6: Raman spectra of R6G of various molar concentrations adsorbed on a Ag template, which after MWA exhibited LSPR at $633 \mathrm{~nm}$.

Table II: The detected Raman (SERRS) peaks of R6G using the sputtered Ag sample presented in Fig. 1-a2.

\begin{tabular}{|c|c|c|c|c|c|c|c|c|c|}
\hline & \multirow{2}{*}{$\begin{array}{c}\text { Spectral } \\
\text { Position } \\
\left(\mathrm{cm}^{-1}\right)\end{array}$} & \multirow{2}{*}{$\begin{array}{l}\text { Assign- } \\
\text { ment* }\end{array}$} & \multicolumn{7}{|c|}{ Ag, LSPR@633 nm } \\
\hline & & & $1 \mathrm{nM}$ & $5 \mathrm{nM}$ & $10 \mathrm{nM}$ & $50 \mathrm{nM}$ & $100 \mathrm{nM}$ & $10 \mu \mathrm{M}$ & $1 \mathrm{mM}$ \\
\hline 1 & 610 & C-C-C ring & Q & Q & $\checkmark$ & $\checkmark$ & $\checkmark$ & $\checkmark$ & $\checkmark$ \\
\hline 2 & 658 & & Q & $x$ & Q & Q & Q & $\checkmark$ & $\checkmark$ \\
\hline 3 & 771 & \begin{tabular}{|l|}
$\begin{array}{l}\text { C-H out of } \\
\text { plane bend }\end{array}$ \\
\end{tabular} & $\checkmark$ & Q & $\checkmark$ & $\checkmark$ & $\checkmark$ & $\checkmark$ & $\checkmark$ \\
\hline 4 & 925 & & $\checkmark$ & $\checkmark$ & $\checkmark$ & $\checkmark$ & $\checkmark$ & $\checkmark$ & $\checkmark$ \\
\hline 5 & 1010 & $\#$ & Q & Q & $\mathrm{Q}$ & $\checkmark$ & $\checkmark$ & $\checkmark$ & $\checkmark$ \\
\hline 6 & 1123 & $\begin{array}{c}\mathrm{C}-\mathrm{H} \text { in } \\
\text { plane bend }\end{array}$ & $\checkmark$ & $x$ & $\checkmark$ & $\checkmark$ & $\checkmark$ & $\checkmark$ & $\checkmark$ \\
\hline 7 & 1182 & \begin{tabular}{|c|}
$\mathrm{C}-\mathrm{C}$ \\
stretching \\
\end{tabular} & $x$ & Q & $\checkmark$ & $\checkmark$ & $\checkmark$ & $\checkmark$ & $\checkmark$ \\
\hline 8 & 1308 & & $x$ & Q & $\checkmark$ & $\checkmark$ & $\checkmark$ & $\checkmark$ & $\checkmark$ \\
\hline 9 & 1361 & $\begin{array}{l}\text { Aromatic C- } \\
\text { C stretching }\end{array}$ & Q & $\checkmark$ & $\checkmark$ & $\checkmark$ & $\checkmark$ & $\checkmark$ & $\checkmark$ \\
\hline 10 & 1418 & & $x$ & $x$ & $\times$ & Q & $\mathrm{Q}$ & $\checkmark$ & $\checkmark$ \\
\hline 11 & 1506 & \begin{tabular}{|l|} 
Aromatic C- \\
C stretching
\end{tabular} & $\checkmark$ & $\checkmark$ & $\checkmark$ & $\checkmark$ & $\checkmark$ & $\checkmark$ & $\checkmark$ \\
\hline 12 & 1570 & & $\checkmark$ & $\checkmark$ & $\checkmark$ & $\checkmark$ & $\checkmark$ & $\checkmark$ & $\checkmark$ \\
\hline 13 & 1647 & $\begin{array}{l}\text { Aromatic C- } \\
\text { C stretching }\end{array}$ & $\checkmark$ & $\checkmark$ & $\checkmark$ & $\checkmark$ & $\checkmark$ & $\checkmark$ & $\checkmark$ \\
\hline
\end{tabular}

*Ref. 50; "Not observed in Ref. 50.

$\checkmark=$ detected; $x=$ non-existent; Q=Questionable.

In order to quantify the SERRS data, we fitted the five aforementioned dominant Raman peaks of R6G by Lorentzian functions, without any constrain, in Microcal Origin $^{\mathrm{TM}}$. The areas below the Lorentzian functions were scaled taking into account the used power of the 
excitation beam for each spectrum, in order to determine the final Raman intensity of the corresponding peak. The results of this analysis for three sets of samples are presented in Fig. 7. In particular, we compare the SERRS sensitivity for various concentrations and for the five main Raman peaks of R6G between: i) templates with nanoparticles of the same element $(\mathrm{Ag})$ but with different sizes resulting in different LSPR wavelengths $(545 \mathrm{~nm}$ on resonance with the Raman excitation beam, and 633 $\mathrm{nm}$ off resonance with the excitation beam), and ii) templates of nanoparticles of different elements $(\mathrm{Ag}$ and $\mathrm{Au}$ ) but exhibiting LSPR at similar wavelengths (545 and $559 \mathrm{~nm}$, respectively) in order to investigate the potential chemical effects on the SERRS signal. The data of Fig. 7 indicate that all the $\mathrm{Ag}$ nanoparticle templates are exceptionally sensitive for SERRS (especially if we take into account the challenging protocol for R6G adsorption that we followed) and can detect R6G with concentrations down to $1 \mathrm{nM}$. The wavelength of LSPR of the nanoparticles is not a crucial pparameter, as in most cases the SERRS signal is comparable for the two sets of $\mathrm{Ag}$ samples. On the other hand, the $\mathrm{Au}$ nanoparticles template is not that efficient for various reasons, such as i) the worst isolation of $\mathrm{Au}$ nanoparticles (as shown in the AFM image of Fig. 1d2) resulting in less hot spots for R6G adsorption, ii) the weaker LSPR (based on the comparison of DR values for $\mathrm{Au}$ and $\mathrm{Ag}$ in Fig. 4b), and iii) the different surface chemistry of $\mathrm{Ag}$ and $\mathrm{Au}$.

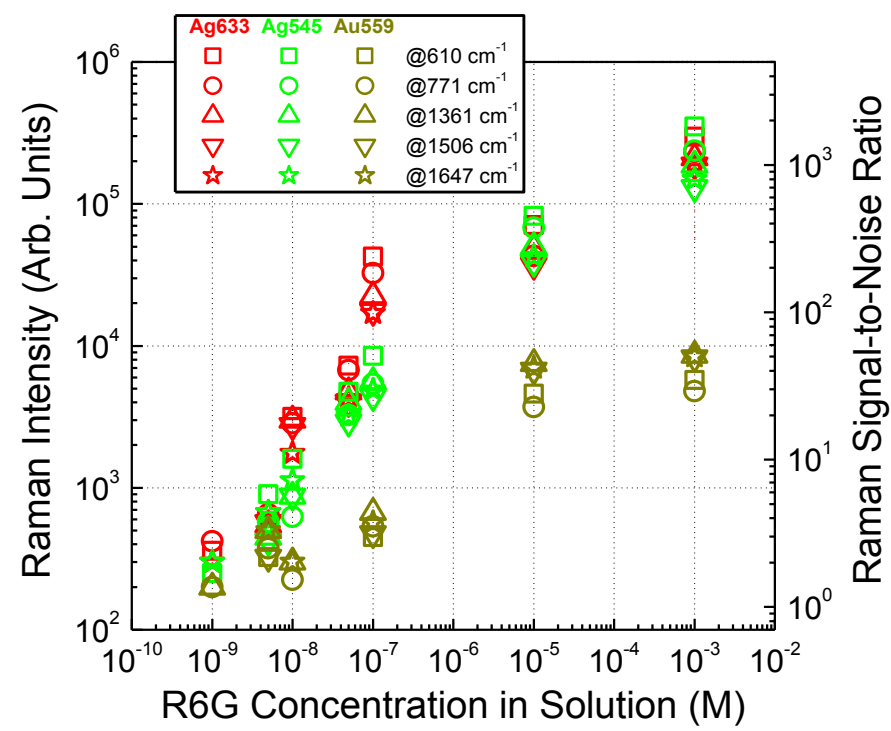

Fig. 7: Quantification results of SERRS measurements of R6G on $\mathrm{Ag}$ and $\mathrm{Au}$ nanoparticle templates produced by MWA.

\section{CONCLUSIONS}

We demonstrated that microwave annealing can be safely applied to metal ultra-thin films with thicknesses below $14 \mathrm{~nm}$. The microwave radiation interacts more efficiently with the underlying doped $\mathrm{Si}$ substrate, than with the metal film itself, providing exceptional potential for accurate, reproducible, fast and reliable fabrication of metal nanoparticles supported on $\mathrm{Si}$. This is a generic process that can be applied to a variety of metals with melting point lower than that of $\mathrm{Cu}$. We provide information on the fundamental parameters for the production of such templates, such as: the metallic element ( $\mathrm{Ag}, \mathrm{Au}, \mathrm{Sn})$, the thickness of the metallic film, the metal deposition technique, and the microwave annealing time. Such supported nanoparticles can be used to a wide variety of applications such as photothermal solar harvesting, enhancement of photovoltaics, photocatalysis, etc. Among the various applications we focused on the plasmonic behavior of such nanoparticle templates, and on their surface-enhanced resonant Raman scattering response, as the most characteristic measure of their plasmonic efficiency. We found that even following an ultra-fast and very challenging protocol for R6G adsorption on the particles the Raman response of the $\mathrm{Ag}$ nanoparticles produced by MWA was successful in detecting R6G in aqueous solutions with concentrations down to $1 \mathrm{nM}$.

\section{ACKNOWLEDGEMENTS}

The research activities that led to these results were cofinanced by Hellenic Funds and by the European Regional Development Fund (ERDF) under the Hellenic National Strategic Reference Framework (NSRF) 2007-

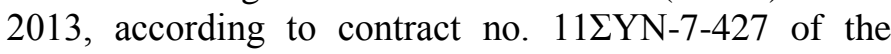
Project 'Surface treatment of multicrystalline silicon solar cells for improved efficiency', within the Program 'Competitiveness and Entrepreneurship'.

\section{REFERENCES}

1. Unique Gold Nanoparticle Aggregates as a Highly Active SurfaceEnhanced Raman Scattering Substrate, A.M. Schwartzberg, C.D. Grant, A. Wolcott, C.E. Talley, T.R. Huser, R. Bogomolni, J.Z. Zhang, Phys. Chem. B 2004, 108, 19191-19197.

2. SERS detection of indirect viral DNA capture using colloidal gold and methylene blue as a Raman label, M.H. Harpster, H. Zhang, A.K. Sankara-Warrier, B.H. Ray, T.R. Ward, J.P. Kollmar, K.T. Carron, J.O. Mecham, R.C. Corcoran, W.C. Wilson, P.A. Johnson, Biosensors and Bioelectronics 2009, 25, 674-681.

3. Plasmostor: a metal-oxide-Si field effect plasmonic modulator, Dionne, J.A.; Diest, K.; Sweatlock, L.A.; Atwater, H.A. Nano Lett. 2009, 9, 897-902.

4. Imprinted Au-Nanoparticle Composites for the Ultrasensitive Surface Plasmon Resonance Detection of Hexahydro-1,3,5-trinitro-1,3,5triazine, Riskin, M.; Tel-Vered, R.; Willner, I. Adv. Mater. 2010, 22, 1387-1391.

5. Nanoplasmonic Probes of Catalytic Reactions, Larsson, E.M.; Langhammer, C.; Zoric, I.; Kasemo, B. Science 2009, 326, 1091-1094.

6. Optical Encoding by Plasmon-Based Patterning: Hard and Inorganic Materials Become Photosensitive, A. Siozios, D.C. Koutsogeorgis, E. Lidorikis, G.P. Dimitrakopulos, Th. Kehagias, H. Zoubos, Ph. Komninou, W.M. Cranton, C. Kosmidis, P. Patsalas, Nano Lett. 2012, 12, 259-263.

7. Surface-Enhanced Raman Scattering (SERS) and Surface-Enhanced Resonance Raman Scattering (SERRS): A Review of Applications, G. McNay, D. Eustace, W.E. Smith, K. Faulds, D. Graham, Appl. Spectr. 2011, 825-837.

8. Progress in plasmonic engineering of surface-enhanced Ramanscattering substrates toward ultra-trace analysis, G.A. Baker, D.S. Moore, Anal Bioanal Chem (2005) 382: 1751-1770. 
9. Plasmons in Strongly Coupled Metallic Nanostructures, N.J. Halas, S La, W.-S. Chang, S. Link, P. Nordlander, Chem. Rev. 2011, 111, 3913 3961.

10. Surface-enhanced Raman scattering and biophysics, K. Kneipp, H Kneipp, I. Itzkan, R.R. Dasari, M.S. Feld, J. Phys.: Condens. Matter 14 (2002) R597-R624

11. Templated Techniques for the Synthesis and Assembly of Plasmonic Nanostructures, M.R. Jones, K.D. Osberg, R.J. Macfarlane, M.R. Langille, C.A. Mirkin, Chem. Rev. 2011, 111, 3736-3827.

12. Single-Molecule and Single-Nanoparticle SERS: Examining the Roles of Surface Active Sites and Chemical Enhancement, W.E. Doering, S. Nie, J. Phys. Chem. B 2002, 106, 311-317.

13. Probing the Structure of Single-Molecule Surface-Enhanced Raman Scattering Hot Spots, J.P. Camden, J.A. Dieringer, Y. Wang, D.J. Masiello, L.D. Marks, G.C. Schatz, R.P. Van Duyne, J. Am. Chem. Soc. 2008, 130, 12616-12617

14. Rapid Detection of an Anthrax Biomarker by Surface-Enhanced Raman Spectroscopy, X. Zhang, M.A. Young, O. Lyandres, R.P. Van Duyne, J. Am. Chem. Soc. 2005, 127, 4484-4489.

15. SERS Classification of Highly Related Performance Enhancers, R.A Alvarez-Puebla, J.P. Bravo-Vasquez, B. Cui, T. Veres, H. Fenniri, Chem. Med. Chem. 2007, 2, 1165-1167.

16. Vibrational characterization and surface enhanced Raman scattering detection of probenecid doping drug, I. Izquierdo-Lorenzo, J.V. GarcíaRamos, S. Sanchez-Cortes, J. Raman Spectrosc. 2013, 44, 1422-1427.

17. Controlling the Synthesis and Assembly of Silver Nanostructures for Plasmonic Applications, M. Rycenga, C.M. Cobley, J. Zeng, W. Li, C.H. Moran, Q. Zhang, D. Qin, Y. Xia, Chem. Rev. 2011, 111, 36693712.

18. Shell-isolated nanoparticle-enhanced Raman Spectroscopy, J.-F. Li, Y.F. Huang, Y. Ding, Z.-L. Yang, S.-B. Li, X.-S. Zhou, F.-R. Fan, W. Zhang, Z.-Y. Zhou, D.-Y. Wu, B. Ren, Z.-L. Wang, Z.-Q. Tian, Nature 2010, 464, 392-395.

19. Surface-enhanced Raman scattering on tunable plasmonic nanoparticle substrates, J.B. Jackson, N.J. Halas, Proc. Nat. Acad. Sci. USA 2004, 101, 17930-17935.

20. Monodisperse Hexagonal Silver Nanoprisms: Synthesis via ThiolateProtected Cluster Precursors and Chiral, Ligand-Imprinted SelfAssembly, N. Cathcart, V. Kitaev, ACS Nano, 2011, 5, 7411-7425.

21. Toward a Glucose Biosensor Based on Surface-Enhanced Raman Scattering, K.E. Shafer-Peltier, C.L. Haynes, M.R. Glucksberg, R. P. Van Duyne, J. Am. Chem. Soc. 2003, 125, 588-593.

22. Chemically Patterned Microspheres for Controlled Nanoparticle Assembly in the Construction of SERS Hot Spots, G. Braun, I. Pavel, A.R. Morrill, D.S. Seferos, G.C. Bazan, N.O. Reich, M. Moskovits, J. Am. Chem. Soc. 2007, 129, 7760-7761.

23. Double-Resonance Plasmon Substrates for Surface-Enhanced Raman Scattering with Enhancement at Excitation and Stokes Frequencies, Y. Chu, M.G. Banaee, K.B. Crozier, ACS Nano 2010, 4, 2804-2810.

24. Single Molecule Directivity Enhanced Raman Scattering using Nanoantennas, A. Ahmed, R. Gordon, Nano Letters 2012, 12 , 2625-2630.

25. Chemical seeded growth of Ag nanoparticle arrays and their application as reproducible SERS substrates, A. Sánchez-Iglesias, P. AldeanuevaPotel, W. Ni, J. Pérez-Juste, I. Pastoriza-Santos, R.A. Alvarez-Puebla, B.N. Mbenkum, L.M. Liz-Marzán, Nano Today 2010, 5, 21-27.

26. Engineering the plasmon resonance of large area bimetallic nanoparticle films by laser nanostructuring for chemical sensors, M.J. Beliatis, S.J. Henley, S.R.P. Silva, Opt. Lett. 2011, 36 1362-1364.

27. Near field properties of nanoparticle arrays fabricated by laser annealing of thin $\mathrm{Au}$ and $\mathrm{Ag}$ films, S. Imamova, N. Nedyalkov, A. Dikovska, P. Atanasov, M. Sawczak, R. Jendrzejewski, G. Sliwinski, M. Obara, Appl. Surf. Sci. 2010, 257, 1075-1079.

28. Formation of silicides in a cavity applicator microwave system, D.C Thompson, H.C. Kim, T.L. Alford, J.W. Mayer, Appl. Phys. Lett. 2003, 83, 3918-3921

29. Dopant activation in ion implanted silicon by microwave annealing, T.L Alford, D.C. Thompson, J.W. Mayer, N.D. Theodore, J. Appl. Phys. 2009, 106, 1149021-1149028.

30. Crystallization of amorphous Si film by microwave annealing with $\mathrm{SiC}$ susceptors, S.C. Fong, C.Y. Wang, T.H. Chang, T.S. Chin, Appl. Phys Lett. 2009, 94, 102104-102106.

31. Redistribution of dopant during microwave annealing of a multilayer structure for production $\mathrm{p}-\mathrm{n}$ junction, E.L. Pankratov, J. Appl. Phys. 2008, 103, 0643201-06432010.

32. Controllable growth of silver nanostructures by a simple replacement reaction and their SERS studies, W. Ye, C. Shen, J. Tian, C. Wang, C. Hui, H. Gao, Sol. Stat. Sci. 2009, 11, 1088-109.
33. Surface Enhanced Raman Spectroscopy of Individual Rhodamine 6G, Molecules on Large Ag Nanocrystals, A.M. Michaels, M. Nirmal, L.E. Brus, J. Am. Chem. Soc. 1999, 121, 9932-9939.

34. Surface-Enhanced Raman and Fluorescence Spectroscopy of Dye Molecules Deposited on Nanostructured Gold Surfaces, A. Merlen, F. Lagugné-Labarthet, E. Harté, J. Phys. Chem. C 2010, 114, 1287812884 .

35. The controlled pulsed laser deposition of $\mathrm{Ag}$ nanoparticle arrays for surface enhanced Raman scattering, C. D'Andrea, F. Neri, P.M. Ossi, N. Santo, S. Trusso, Nanotechnology 2009, 20, 2456061-2456065.

36. Full sintering of powdered-metal bodies in a microwave field, R. Roy, D. Agrawal, J. Cheng, and S. Gedevanishvili, Nature 1999, 399, 668670 .

37. The sonochemical and microwave-assisted synthesis of nanosized YAG particles, Y. Letichevsky, L. Sominski, J. Calderon Moreno, A. Gedanken, New J. Chem. 2005, 29, 1445-1449.

38. Simple and rapid synthesis of $\mathrm{MgO}$ with nano-cube shape by means of a domestic microwave oven, N. Takahashi, Sol. Stat. Sci. 2007, 9, 722724.

39. Processing Core/Alloy/Shell Nanoparticles: Tunable Optical Properties and Evidence for Self-Limiting Alloy Growth, W. Wu, P.N. Njoki, H. Han, H. Zhao, E.A. Schiff, P.S. Lutz, L. Solomon, S. Matthews, M.M. Maye, J. Phys. Chem. C 2011, 115, 9933-9942.

40. W. Chen, M.D. Thoreson, S. Ishii, A.V. Kildishev, V.M. Shalaev, Ultrathin ultra-smooth and low-loss silver films on a germanium wetting layer, Opt. Expr. 2010, 18, 5124-5134.

41. Size Effects on the Melting Temperature of Silver Nanoparticles: In-situ TEM Observations, M.A. Asoro, J. Damiano, P.J. Ferreira, Microsc. Microanal. 2009, 15, 706-707.

42. Effect of Nanoparticle Size on the Onset Temperature of Surface Melting, A.P. Chernyshev, Mater. Lett. 2009, 63, 1525-1527.

43. Determination of Complete Melting and Surface Premelting Points of Silver Nanoparticles by Molecular Dynamics Simulation, H.A. Alarifi, M. Atiş, C. Özdoğan, A. Hu, M. Yavuz, Y. Zhou, J. Phys. Chem. C 2013, 117, 12289-12298.

44. Kinetics of Ag nanoparticle growth in thick $\mathrm{SiO}_{2}$ films: an in situ optical assessment of Ostwald ripening, J.A. Jimenez, M. Sendova, Mater. Chem. Phys. 2012, 135, 282-286.

45. Wetting of silicon single crystal by silver and tin, and their interfaces, $\mathrm{S}$. Sugihara, K. Okazaki, K. Suganuma, J. Mater. Sci. 1993, 28, 2455 2458.

46. Functionally-graded poly(dimethylsiloxane)/silver nanocomposites with tailored broadband optical absorption, P. Nikolaou, C. Mina, M. Constantinou, L.E. Koutsokeras, G. Constantinides, E. Lidorikis, A. Avgeropoulos, P.C. Kelires, P. Patsalas, Thin Solid Films 2015, in press.; doi:10.1016/j.tsf.2014.11.063.

47. Effect of Different Pretreatments on Through Silicon Via Copper Filling, Y. Li, Haiyong Cao, Xue Feng, Huiqin Ling, Ming Li, Jiangyan Sun, IEEE Electronic Packaging Technology (ICEPT), 2013 14th International Conference on, $169-172$

48. Drastic Reduction of Plasmon Damping in Gold Nanorods, C. Sönnichsen, T. Franzl, T. Wilk, G. von Plessen, J. Feldmann, O. Wilson, P. Mulvaney, Phys. Rev. Lett. 2002, 88, 0774021- 0774024.

49. Influence of localized surface plasmon resonance and free electrons on the optical properties of ultrathin Au films: a study of the aggregation effect, X.D. Li, T.P. Chen, Y. Liu, K.C. Leong, Optics Express, 2014 22, 5124-5132.

50. Surface-enhanced resonance Raman spectroscopy of Rhodamine 6G adsorbed on colloidal silver, P. Hildebrandt, M. Stockburger, J. Phys. Chem. 1984, 88, 5935-5944. 


\section{ON LINE SUPPORTING INORMATION}

\section{A. MICROSTRUCTURE AND MORPHOLOGY}

\section{A1. AFM Analysis}

The samples surface morphology was characterized by Atomic Force Microscopy (AFM). AFM was mounted in an anti-vibrational air stable granite stage installed inside an acoustic enclosure. Tapping mode was utilized for better image acquisition using extra sharp rectangular silicon cantilevers to reduce the AFM's minimum detectable size (nominal tip radius: $8 \mathrm{~nm}$ ) with a force constant of $40 \mathrm{~N} / \mathrm{m}$ (MPP-1112010). $2 \times 2 \mu \mathrm{m} 2$ images were obtained and the distribution of the size of the particles was derived though grain analysis. A direct comparison on the size and the shape of the particles before and after microwave annealing was possible through the acquisition of detailed high resolution images (at 500 $\mathrm{nm})$ and subsequent cross section analysis.

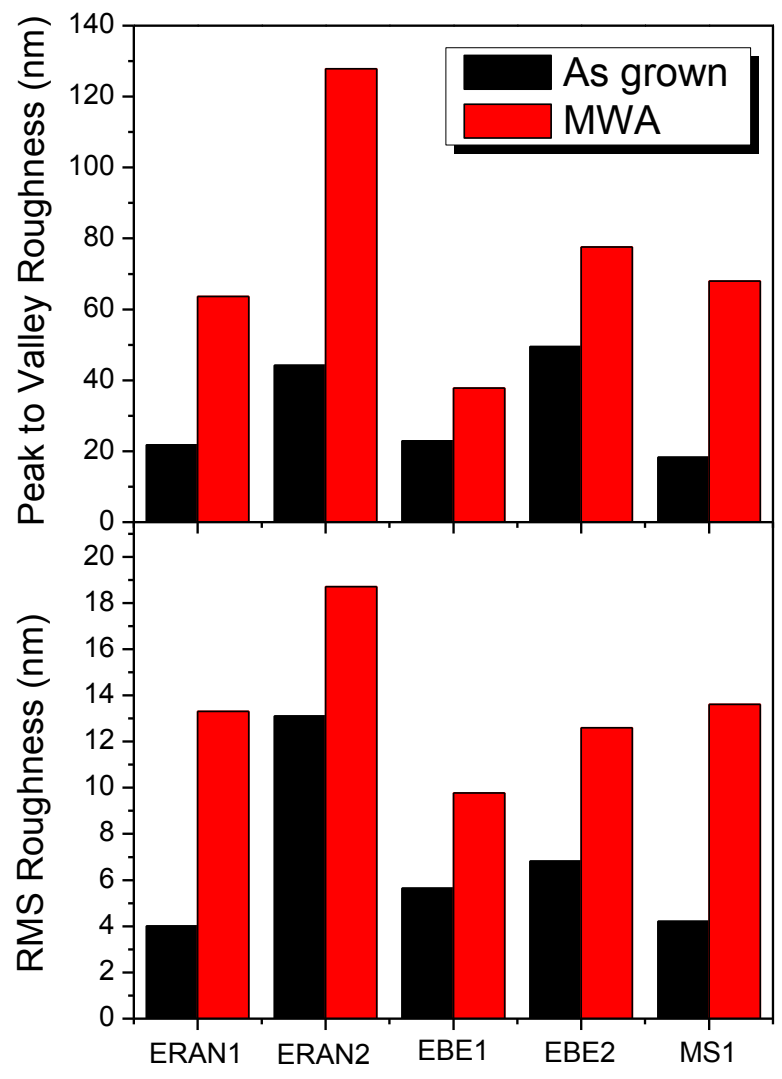

Fig. S1. particular, XRR revealed that the density values of the sputtered $\mathrm{Ag}$ layers are dramatically reduced from 5.6 $\mathrm{g} / \mathrm{cm}^{3}$ to $2.3 \mathrm{~g} / \mathrm{cm}^{3}$ after MWA, as it is shown in Fig. 2, due to the transformation of a quasi-continuous film to individual isolated nanoparticles. XPS provides further evidence; in Fig. 3 the $\mathrm{Si}-2 p$ and $\mathrm{Ag}-3 d$ high resolution photoelectron peaks are presented. It is evident that the relative strength of the $\mathrm{Si}-2 p$ peak is substantially increased after MWA because of the exposure of bare Si surface due to the self-organization of Ag from a quasicontinuous layer into nanoparticles. In addition, XPS did not detect any spectral shifts of the Ag-3d peak upon MWA, proving that this microwave process does not influence the chemical bonding of $\mathrm{Ag}$ and no oxidation occurred during MWA.

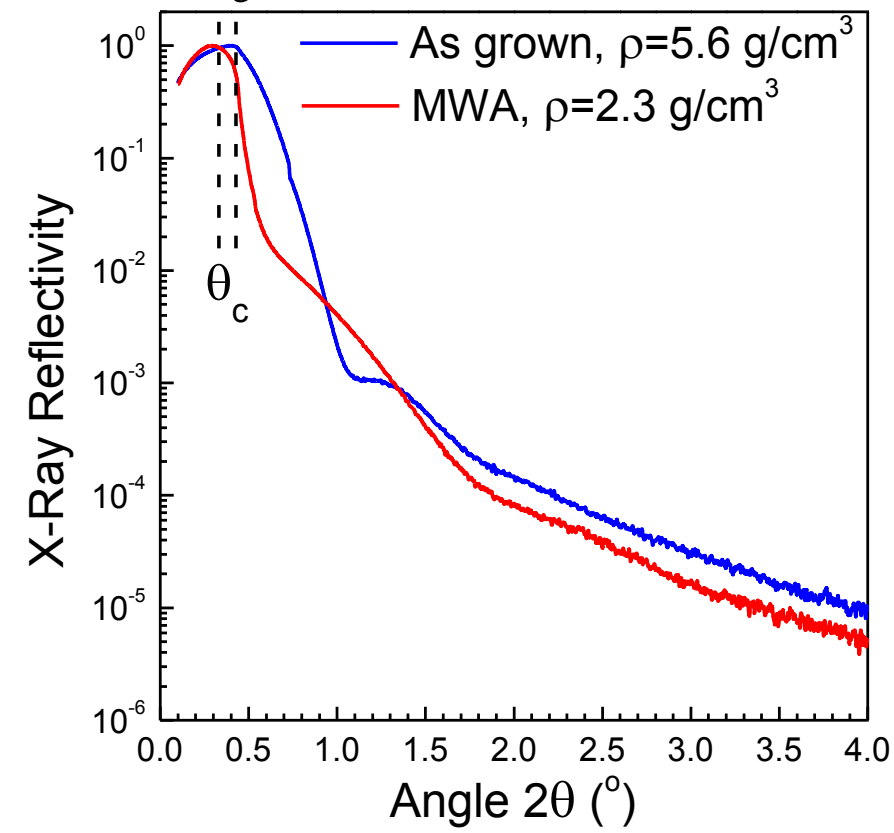

Fig. S2: XRR from a sputtered film before (blue line) and after MWA (red line); the change in the critical angle $\theta_{\mathrm{c}}$ indicates substantial density reduction.

\section{A3. XPS Analysis}

\section{A2. XRR Analysis}

The formation of $\mathrm{Ag}$ nanoparticles after fast MWA was also confirmed by XRR and XPS. In 


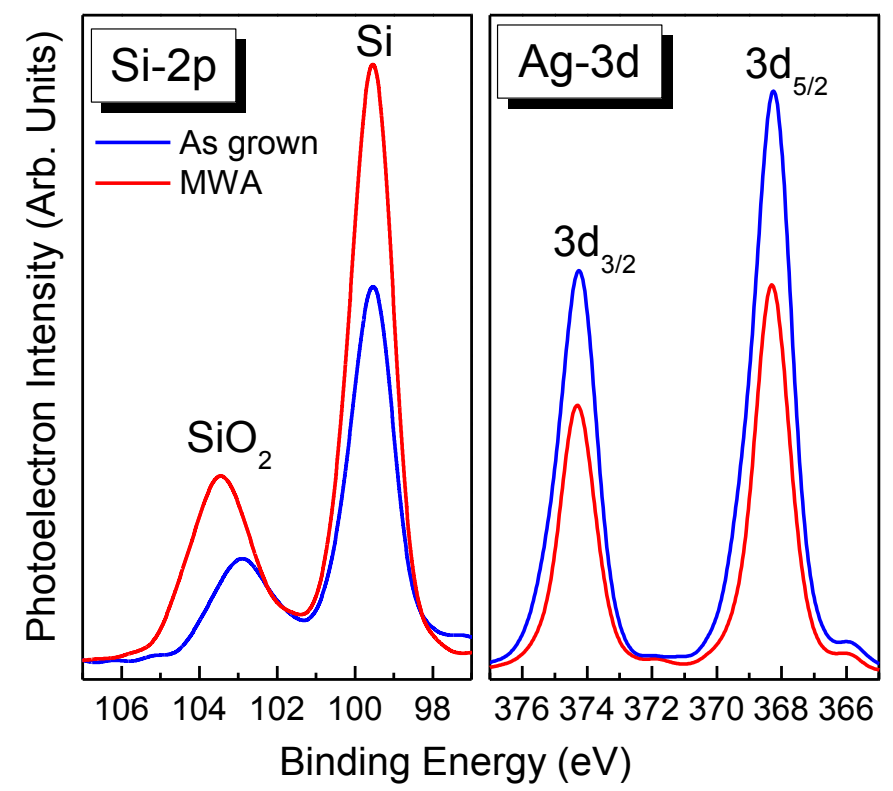

Fig. S3: XPS high resolution spectra of the Si-2p and Ag$3 \mathrm{~d}$ peaks before (blue lines) and after MWA (red lines). 


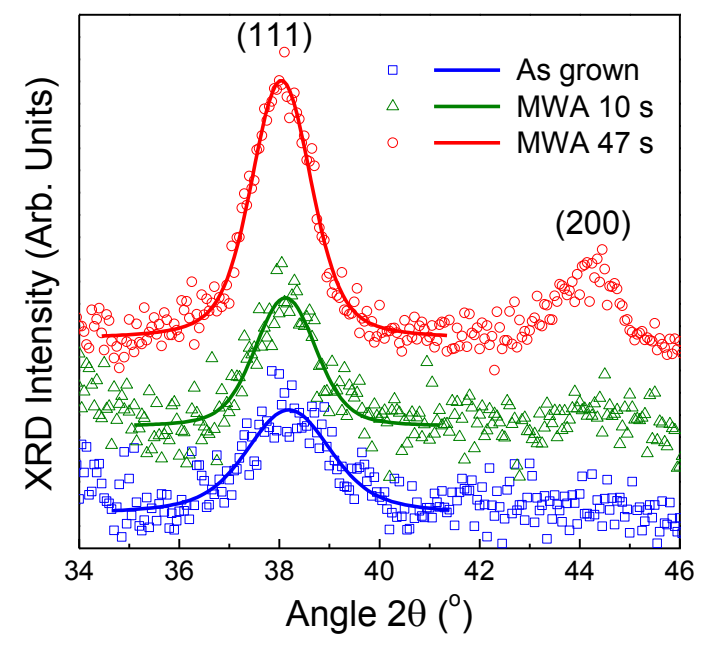

Fig. S4.

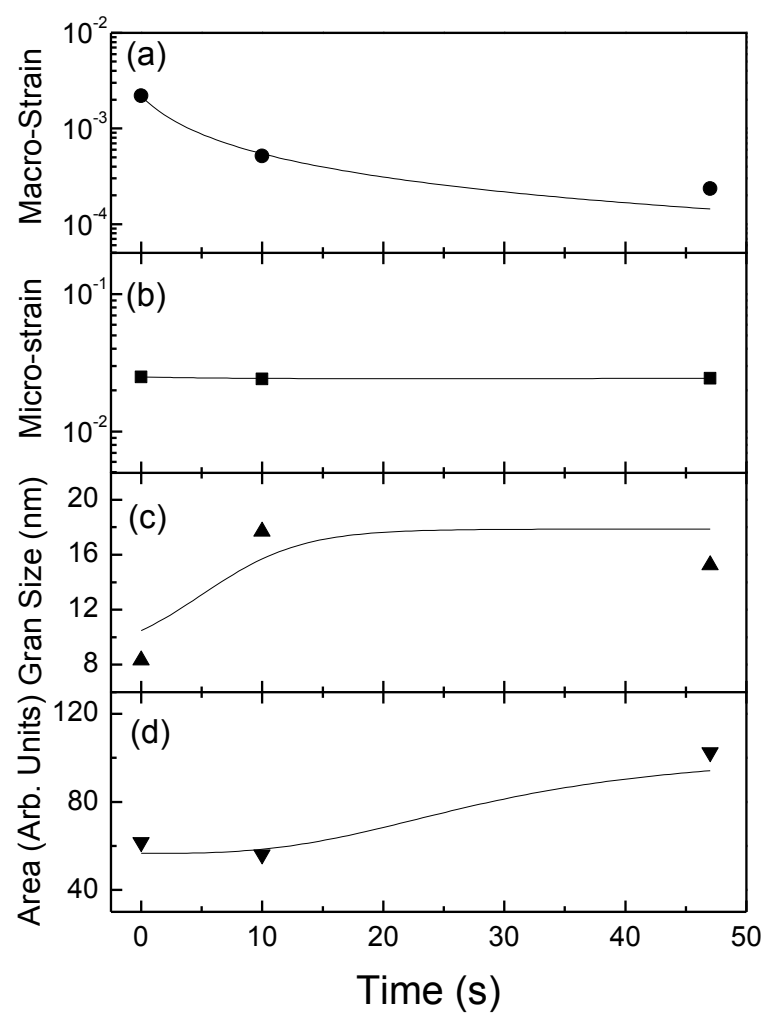

Fig. S5.

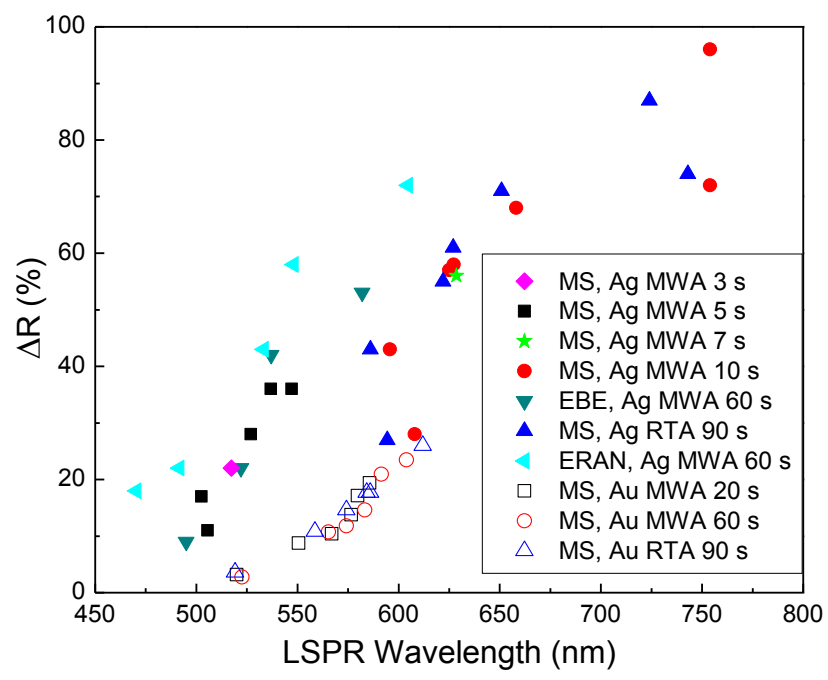

Fig. S6.

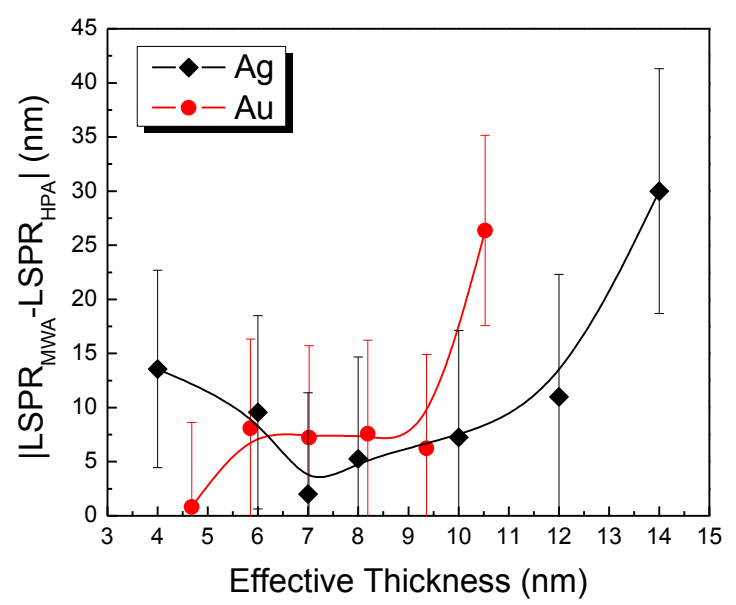

Fig. S7. 

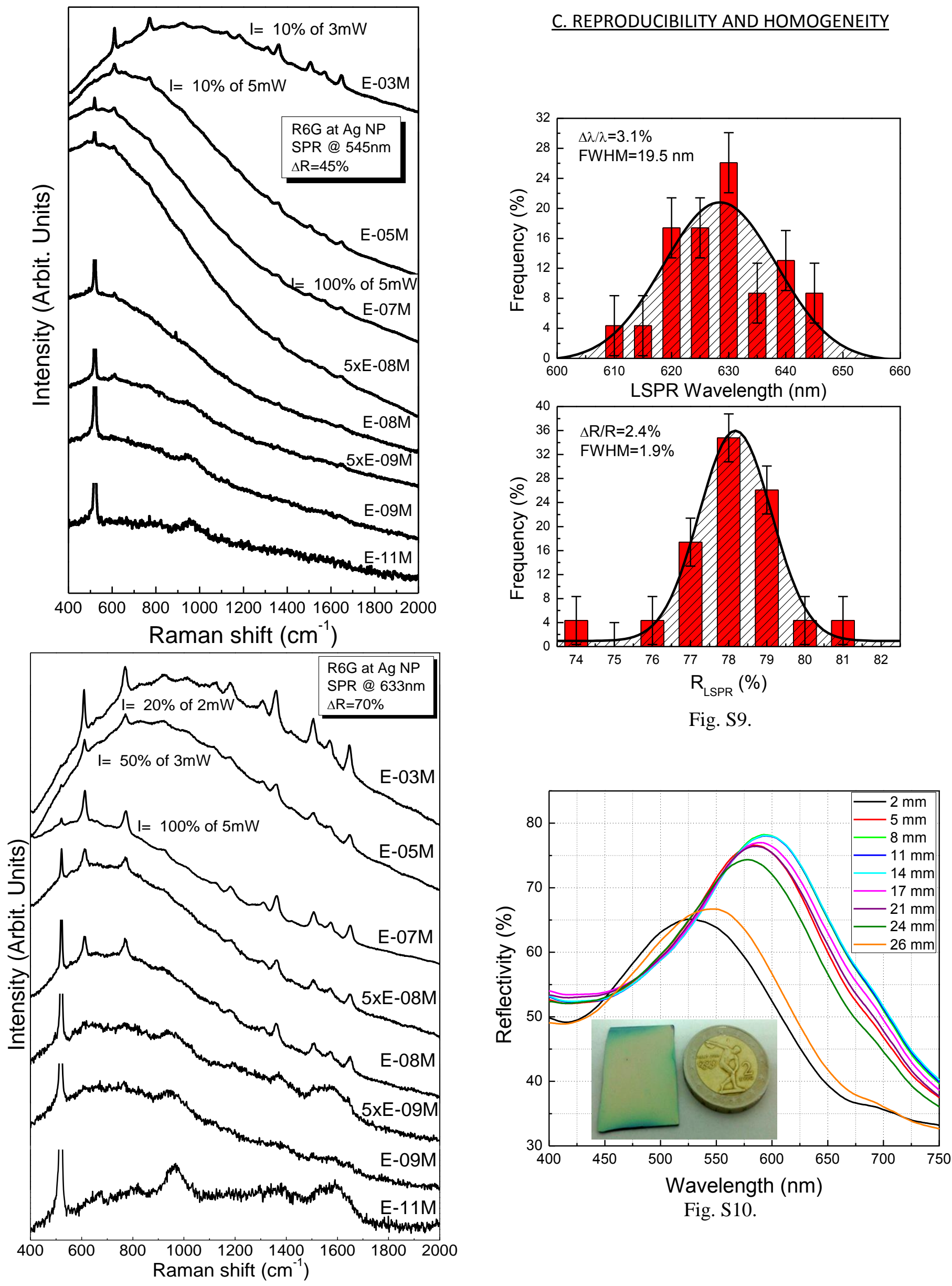

Fig. S10.

Fig. S8: SERS R6G, $545 \mathrm{~nm}$ vs. $633 \mathrm{~nm}$. 